\title{
Contribuição da precipitação de mesoescala para o volume de água armazenada no reservatório de Boqueirão
}

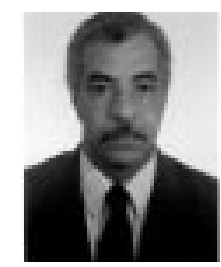

Manoel F. Gomes Filho ${ }^{1}$, Carlos O. Galvão ${ }^{2}$, Rita M. Ricarte ${ }^{3}$, Maria C. L. da Silva ${ }^{3}$, Alana de L. Pontes ${ }^{4} \&$ Carmem T. Becker ${ }^{5}$

1 UFCG/DCA. R. Aprígio Veloso 882, CEP 58109-970, Campina Grande, PB. E-mail: mano@dca.ufcg.edu.br (Foto)
2 UFCG/DEC. E-mail: galvao@dec.ufcg.edu.br
${ }^{3}$ Estudante de Meteorologia/UFCG. E-mail: michelinericarte@yahoo.com.b, cristina@dca.ufcg.edu.br
${ }^{4}$ Estudante de Meteorologia, Bolsista PIBIC/CNPq/UFCG. E-mail: alanadelima@bol.com.br
${ }^{5}$ LMRS/PB. R. Aprígio Veloso 882, CEP 58109-970, Campina Grande,PB. E-mail: carmem@Imrs-semarh.ufcg.edu.br

Protocolo 178 - 26/11/2002 - Aprovado em 12/8/2003

\begin{abstract}
Resumo: Apresenta-se uma análise da influência do sistema convectivo de mesoescala, que ocorreu no início da noite do dia 14 de fevereiro do ano 2002, sobre o volume de água armazenada no reservatório de Boqueirão, na Paraíba. Esta análise foi realizada a partir da precipitação e do volume observado no período de atuação do sistema e mostra que, na verdade, a sua atividade começou no início da noite do dia 14 e se estendeu até a madrugada do dia 15. Para avaliar a contribuição desse sistema para o volume de água acumulado no reservatório, foram utilizados valores horários do volume e precipitação observados, imagens de satélite e outras variáveis meteorológicas relevantes. $O$ resultado mostra aumento pronunciado no volume armazenado neste reservatório, devido à precipitação do sistema, o que causou a suspensão do racionamento de água no município de Campina Grande, cujo abastecimento é realizado por este reservatório.
\end{abstract}

Palavras-chave: precipitação, sistema convectivo de mesoescala e racionamento de água

\section{Contribution of mesoscale precipitation for the volume of water stored in the Boqueirão Reservoir}

\begin{abstract}
An analysis of the influence of an atmospheric mesoscale system which occurred on Thursday, February 14, 2002, on the volume of water stored in the Boqueirão Reservoir of the Paraíba State in Northeast Brazil is presented here. This analysis was made through the observed precipitation and volume for the period of the occurrence of the system and it shows that the largest activity of this system occurred early in the night of Feb. 14 and continued through the morning of Feb. 15. To evaluate the contribution of this system to the volume of the reservoir, hourly observed volumes and precipitation, satellite images and other meteorological variables were used and the result showed a pronounced increase in the volume of this reservoir due to the precipitation of that system which caused the end of water rationing in the municipality of Campina Grande.
\end{abstract}

Key words: precipitation, mesoscale convective system, water rationing

\section{INTRODUÇÃO}

Os distúrbios no escoamento de leste estão, em geral, associados a sistemas convectivos, são responsáveis pelas elevadas taxas de precipitação sobre os oceanos e áreas costeiras dos continentes tropicais, além de se encontrarem entre os mais significativos aspectos observados na atmosfera tropical. Os principais estudos desse fenômeno referem-se a áreas do Atlântico Norte e Pacífico Norte (Riehl, 1945; 1979; Palmer, 1952 e Simpson et al., 1968). A principal fonte de energia para esses sistemas é o calor latente liberado nas nuvens convectivas (Nitta, 1970 e 1972, e Maddox, 1980). É notória a existência desse tipo de distúrbio no Atlântico Tropical Sul (Yamazaki \& Rao, 1977; Chan, 1990; Velasco \& Fritsch, 1987).

Chan (1990) analisando dados de vento e temperatura do período entre dezembro de 1978 e novembro de 1979, detectou que o período de maior frequiência desses distúrbios está entre os meses de março e agosto.

Gomes Filho et al. (1996) relatam a ocorrência de um sistema semelhante, observado no dia 15 de março de 1994, que provocou precipitações bastante intensas na Paraíba, com trovoadas e ventos com grande intensidade.

No período de março a junho, freqüentemente ocorre, sobre a Paraíba, propagação de sistemas de mesoescala, que se originam sobre o Oceano Atlântico, quando as condições estão 
propícias, e se deslocam sobre o continente, seguindo uma trajetória praticamente zonal, atingindo o sertão Paraibano. Geralmente, esses sistemas se originam de perturbações ao sul da Zona de Convergência Intertropical (ZCIT). Eles costumam sofrer uma intensificação bastante acentuada quando interagem com a topografia, sobretudo com as serras da Borborema, na região do agreste e do Teixeira, no sertão. Este efeito é sentido, de modo particular, na precipitação associada a esses sistemas, uma vez que apresentam dois picos exatamente sobre essas regiões serranas (Gomes Filho et al., 1996). A precipitação observada na passagem desses sistemas é, em geral, acompanhada por rajadas de vento muito fortes e trovoadas, tem curta duração e é bastante intensa.

O objetivo deste trabalho é descrever a propagação de um desses sistemas, ocorrido entre o início da noite do dia 14 e a madrugada do dia 15 de fevereiro de 2002, o mais intenso dentre os verificados naquele ano, em termos de precipitação e que, ao elevar o nível do Açude de Boqueirão (Figura 1 para sua localização) provocou a suspensão do racionamento de água, que estava estabelecido desde o ano 2000 na região de Campina Grande, cidade localizada no agreste paraibano, que fica a uma distância de 120 km do litoral.

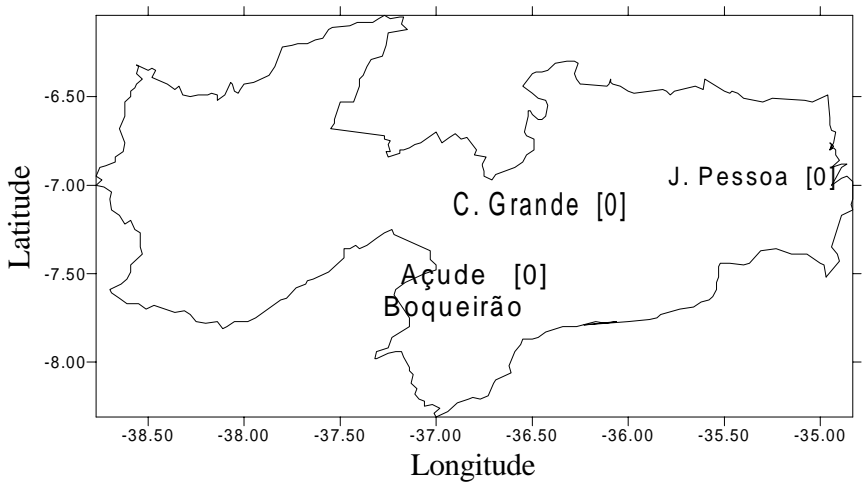

Figura 1. Localização do açude de Boqueirão, no Estado da Paraíba

\section{MATERIAL E MÉTODOS}

A metodologia utilizada neste trabalho consiste, basicamente, em métodos observacionais convencionais e análise de imagens de satélite. Procurou-se relacionar a trajetória do sistema com a sua precipitação observada ao longo da mesma e, ao mesmo tempo, observar a interação do sistema com a topografia. As condições sinóticas são constatadas através dos campos diagnósticos do NMC - National Meteorological Center, USA. Foram consideradas imagens do satélite Meteosat4 (Figura 2) no canal infravermelho, setorizadas para a Região Nordeste, no período entre 21:00 GMT do dia 14 e 6:00 GMT do dia 15 , além de dados de precipitação de 40 postos pluviométricos localizados na área em estudo, para os dias 14 e 15 do mês de fevereiro de 2002. Esclarece-se que a maior parte dos dados de precipitação foi obtida da rede de monitoramento do Laboratório de Meteorologia, Recursos Hídricos e Sensoriamento Remoto da Paraíba - LMRS, PB. Nesta rede, a observação é realizada às $7 \mathrm{~h}$ da manhã. Há de se esperar, portanto, que a precipitação causada por qualquer sistema depois deste horário só seja registrada no dia seguinte. Para analisar as condições sinóticas que concorreram para a formação do sistema, utilizaram-se os campos de vento do modelo de circulação global do NMC em níveis baixos, próximos à superfície e em níveis superiores da atmosfera.

\section{RESULTADOS E DISCUSSÃO}

A análise dos campos de grande-escala para os dias 14 e 15 de fevereiro revela que, desde o horário das 12 GMT do dia 14, o campo das linhas de corrente já apresentava ondulações provenientes de leste (Figuras 3 e 4), a exemplo do caso mostrado por Gomes Filho et al. (1996); isto também pode ser observado através do campo da divergência que, em toda a troposfera, apresentava um padrão de valores positivos e negativos alternados (Figuras 5 e 6). Coerentemente, o campo do movimento vertical apresenta, sobre a área relativa aos Estados do Rio Grande do Norte, Paraíba e litoral de Pernambuco, movimentos ascendentes fortes (Figura 7). A nebulosidade apresentada na Figura 2 está compatível com esses campos de grande escala e o sistema convectivo intenso mostrado na imagem do satélite das 00 GMT do dia 15 , reflete a intensidade do movimento vertical ascendente.
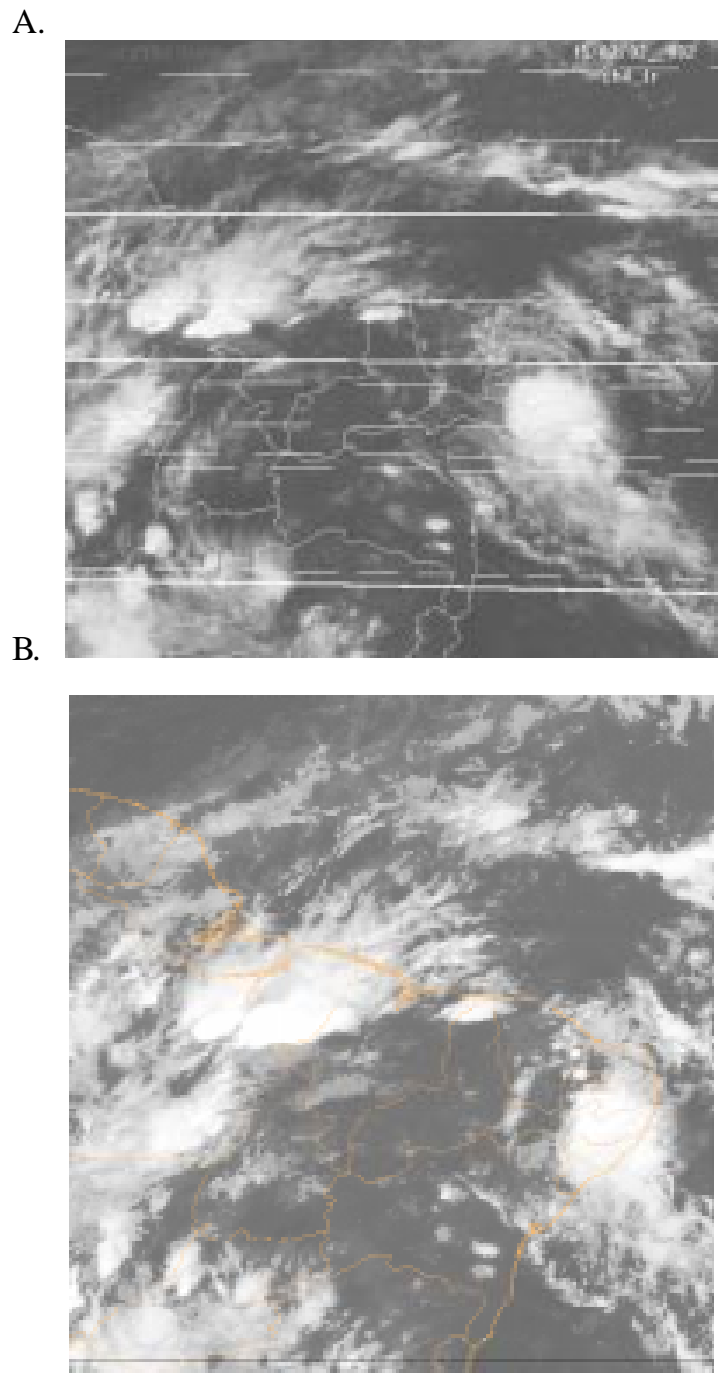

Figura 2. Imagens do satélite Meteosat 4 no canal infravermelho para o dia 15 de fevereiro do ano 2002 mostrando o sistema convectivo nos horários das 00 GMT (A) e 02 GMT (B) 
A.

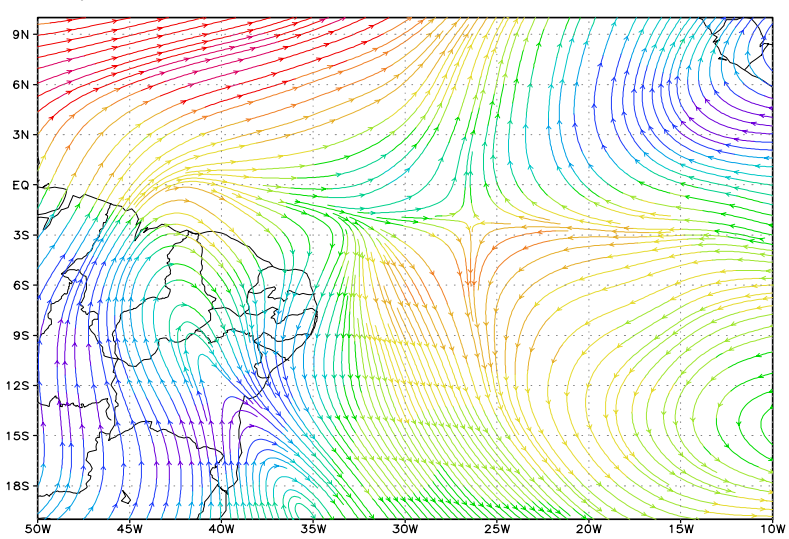

B.

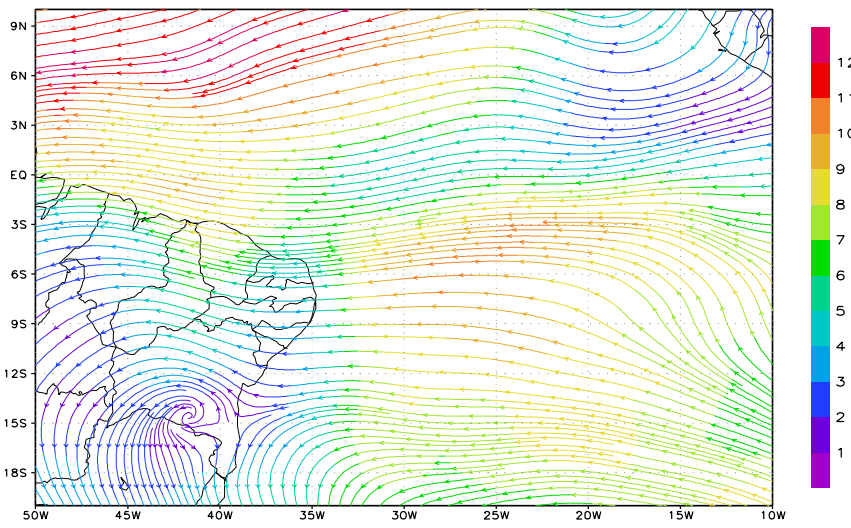

Figura 3. Campo das linhas de corrente para o dia 14 de fevereiro de 2002 às 12 GMT, nos níveis de 200 (A) e 850 hPa (B)

A.

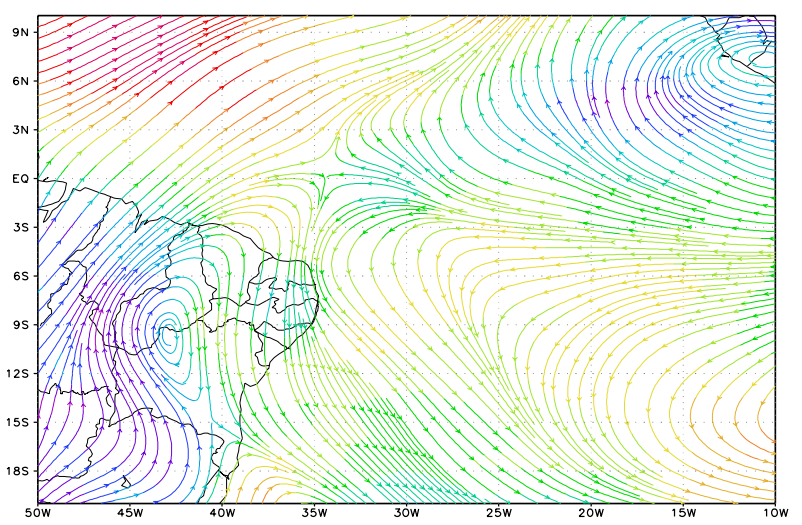

B.

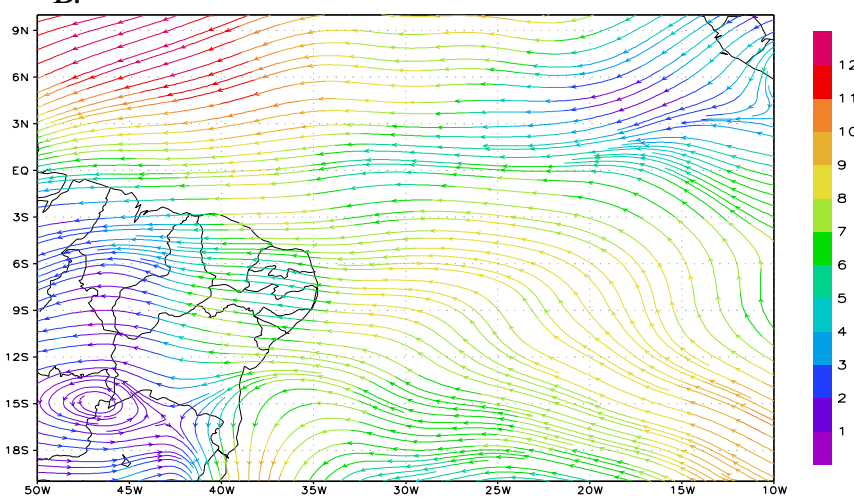

Figura 4. Campo das linhas de corrente para o dia 15 de fevereiro de 2002 às 00 GMT, para os níveis de 200 (A) e 850 hPa (B)
A.

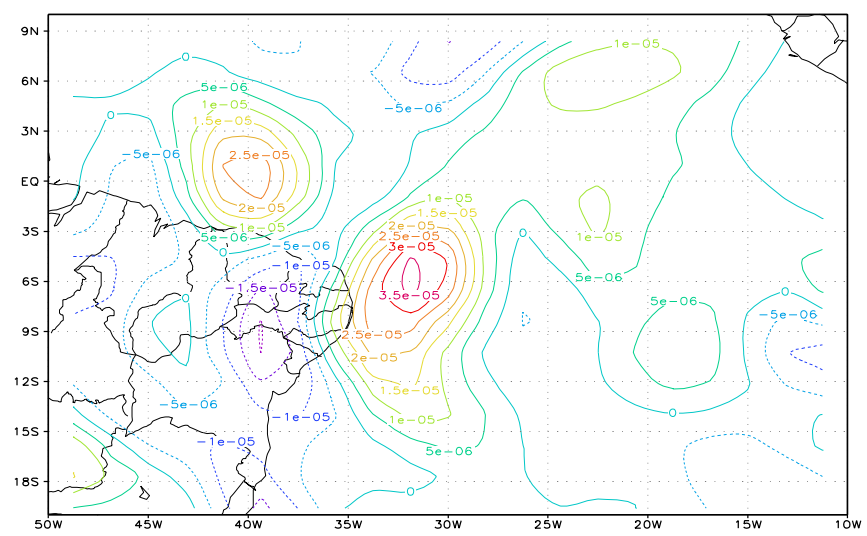

B.

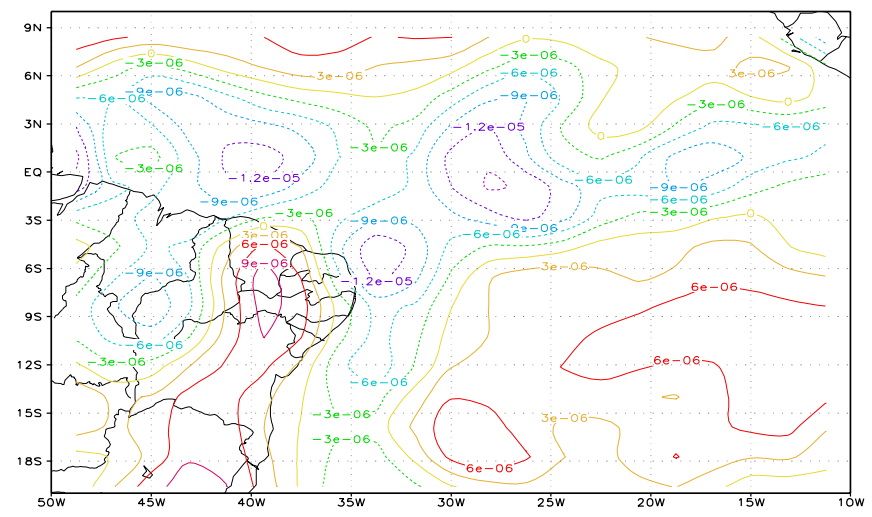

Figura 5. Campo da divergência horizontal, calculada com o vento observado no dia 14 de fevereiro de 2002 às 12 GMT nos níveis de 200 (A) e $1000 \mathrm{hPa}$ (B)

A.

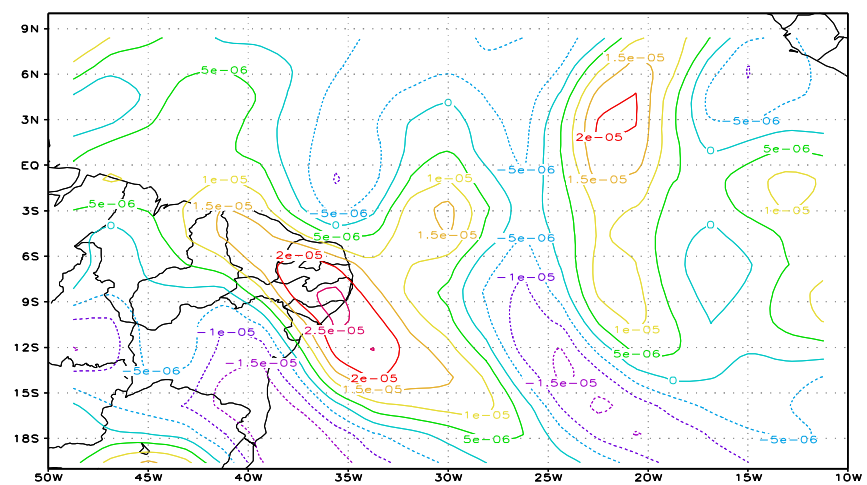

B.

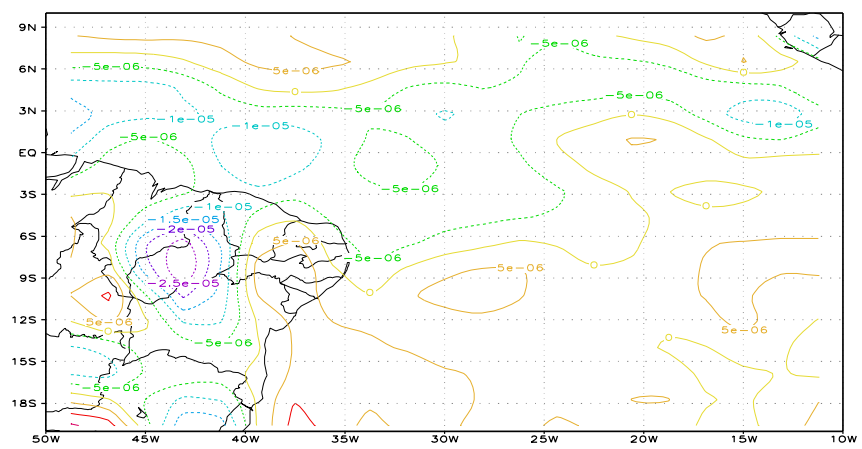

Figura 6. Campo da divergência horizontal, calculada com o vento do dia 15 de fevereiro de 2002 às 00 GMT para os níveis de 200 (A) e $1000 \mathrm{hPa}$ (B) 


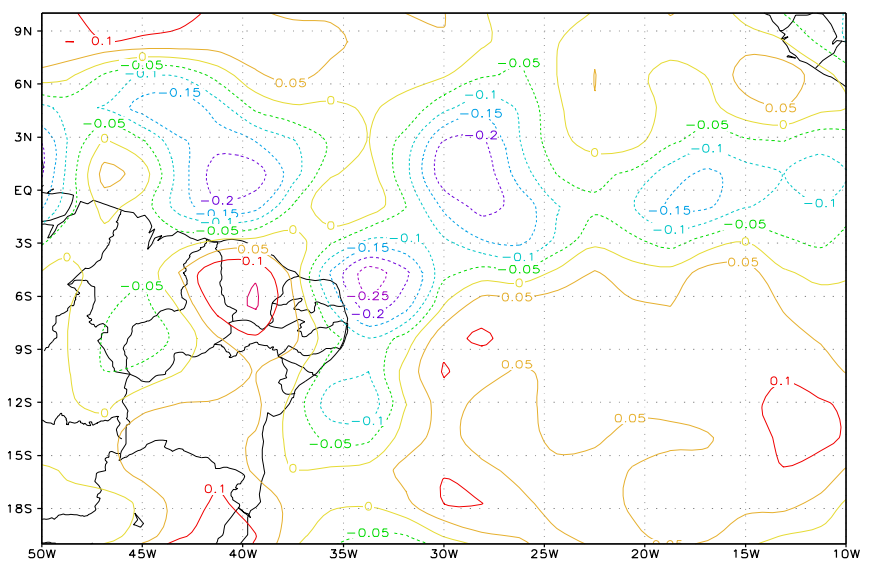

Figura 7. Campo da velocidade vertical Omega $\left(\mathrm{mb} \mathrm{s}^{-1}\right)$ no nível isobárico de $850 \mathrm{hPa}$, para o dia 14 de fevereiro de 2002 às $12 \mathrm{GMT}$

A precipitação associada a este sistema, mostrada na Figura 8 para o dia 15 de fevereiro, ficou mais ou menos concentrada na área sob a cobertura das nuvens, de forma arredondada, que aparece na imagem das 00 GMT do dia 15. Esta precipitação causou aumento percentual no volume armazenado no açude de Boqueirão, que abastece a cidade de Campina Grande, de pelo menos $10 \%$ de sua média histórica, o que equivale a aproximadamente 35 milhões de metros cúbicos de água (Figuras 9).

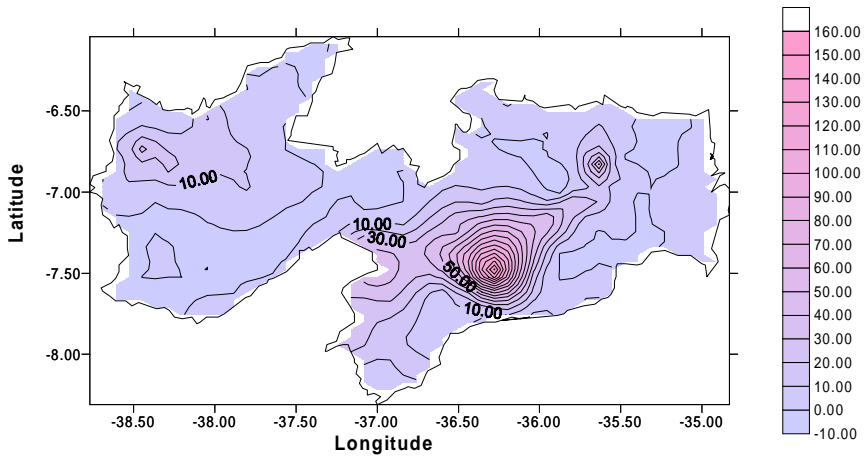

Figura 8. Precipitação observada $(\mathrm{mm})$ pela rede de postos pluviométricos do LMRS/PB no dia 15 de fevereiro de 2002 na Paraíba

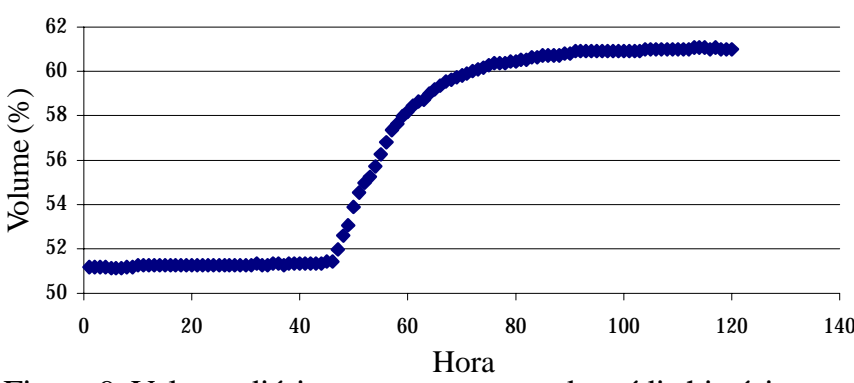

Figura 9. Volume diário em percentagem da média histórica que foi acrescido ao Açude de Boqueirão nos dias 15, 16 e 17 de fevereiro do ano 2002. A hora zero corresponde às $00 \mathrm{GMT}$ do dia 13 de fevereiro de 2002

\section{CONCLUSÕES}

1. A ocorrência de sistemas convectivos de mesoescala sobre o estado da Paraíba, no período que vai de fevereiro a maio, tem importância decisiva para os totais de precipitação da estação chuvosa da região estudada devido à sua relativamente grande freqüência. Alguns desses sistemas contribuem de modo muito significante para a precipitação total sazonal da região.

2. As condições atmosféricas observadas, especialmente a circulação dos ventos em mesoescala, foram decisivas para a formação e desenvolvimento do sistema convectivo e parecem ser precussoras desse tipo de sistema atmosférico.

3. Ele aumentou substancialmente a precipitação na região da bacia do médio Paraíba, onde está localizado o açude de Boqueirão, o que se revestiu de grande significância, pois causou a suspensão do racionamento de água no município de Campina Grande, PB, 350 mil habitantes, que já se estendia desde o ano 2000.

\section{AGRADECIMENTOS}

Os autores expressam seus agradecimentos ao Laboratório de Meteorologia Recursos Hídricos e Sensoriamento Remoto da Paraíba - LMRS/PB, pela prontidão com que cedeu os dados de precipitação e volume do açude estudados, quando da nossa solicitação. Também agradecem ao Departamento de Ciências Atmosféricas, Coordenação de Pós-Graduação em Meteorologia da UFCG e ao CNPq, por tornarem possível a realização deste trabalho, e aos revisores anônimos que contribuíram de forma decisiva para o aprimoramento do texto.

\section{LITERATURA CITADA}

Chan, C.S. Análise de distúrbios ondulatórios de leste sobre o Oceano Atlântico Equatorial Sul. 1990, 134p. INPE-5222TDL/437

Gomes Filho, M.F.; Souza, E.P.; Becker, C.T. Sistemas convectivos de mesoescala com precipitação intensa na Paraíba: um estudo de caso. Revista Brasileira de Meteorologia, v.11, n.1/2, p.36-43. 1996.

Maddox, R.A. Mesoscale convective complexes. Bulletin of the American Meteorological Society, Boston, v.61, p.13741387, 1980.

Nitta, T. A study of generation and conversion of eddy available potential energy in the tropics Journal of the Meteorological Society of Japan, Tokyo, v.48, p.524-528, 1970.

Nitta, T. Energy budget of wave disturbances over Marshall Islands during the years of 1956 and 1958. Journal of the Meteorological Society of Japan, Tokyo, v.50, p.71-84, 1972.

Palmer, C.E. Tropical meteorology. Quarterly Journal of the Royal Meteorological Society, London, v.78, p.126-163, 1952

Riehl, H. Waves in the easterlies and the polar front in the tropics, Chicago: University of Chicago Press, 1945. 79p.

Riehl, H. Climate and weather in the tropics. New York: Academic Press, 1979. 611p.

Simpson, R.H.; Frank, N.; Shindler, D.; Johnson, H.M. The Atlantic hurricane season. Monthly Weather Review, Boston, v.96, p.251-259, 1968.

Velasco, I.; Fritsch, J.M. Mesoscale convective complexes in Americas. Journal of Geophysical Research, Boston, v. 92, n.8, p.9591-9613, 1987.

Yamazaki, Y.; Rao, V.B. Tropical cloudiness over the South Atlantic Ocean. Journal of the Meteorological Society of Japan, Tokyo, v.55, p.205-207, 1977. 